\title{
Where is behavioural ecology going?
}

\author{
lan P.F. Owens
}

Division of Biology and NERC Centre for Population Biology, Imperial College London, Silwood Park, Ascot, Berkshire, UK, SL5 7PY

\begin{abstract}
Since the 1990s, behavioural ecologists have largely abandoned some traditional areas of interest, such as optimal foraging, but many long-standing challenges remain. Moreover, the core strengths of behavioural ecology, including the use of simple adaptive models to investigate complex biological phenomena, have now been applied to new puzzles outside behaviour. But this strategy comes at a cost. Replication across studies is rare and there have been few tests of the underlying genetic assumptions of adaptive models. Here, I attempt to identify the key outstanding questions in behavioural ecology and suggest that researchers must make greater use of model organisms and evolutionary genetics in order to make substantial progress on these topics.
\end{abstract}

'Behavioural ecology is a beguilingly simple subject'

\section{J.R. Krebs and N.B Davies [1]}

\section{The romantic era of behavioural ecology}

The core ideas that underlie modern behavioural ecology can be traced to a period during the 1960s and1970s when a remarkable series of papers demonstrated that simple adaptive models, such as the marginal value theorem, could be used to tackle diverse puzzles that had remained largely untouched during the Modern Synthesis of evolutionary biology [2-14]. Building on the foundations laid by Fisher [15] and Haldane [16], these authors targeted topics as diverse as foraging, fighting, sex and cooperation. The models typically ignored detailed genetic mechanisms and instead predicted that even the most puzzling aspects of behaviour must have evolved because, on average, they increase the fitness of the individual. Such models were not designed to show that animal behaviour is perfectly optimal, but to identify and understand the kinds of payoffs and constraints that are important in behavioural evolution.

With the benefit of hindsight, there were several early works that pioneered the adaptationist approach to empirical studies of behaviour and ecology [17-23] and the fledgling field received popular syntheses in Wilson's Sociobiology [24] and Dawkins' The Selfish Gene [25]. But the conceptual unification of the field and, importantly, its focus on behaviour per se, did not occur until 1978, when Krebs and Davies published the first edition of their edited volume, Behavioural Ecology: An Evolutionary Approach [26]. In the opening sections of that book and in their subsequent introductory textbook [27], Krebs and Davies

Corresponding author: Owens, I.P.F.(i.owens@imperial.ac.uk)

Available online 5 April 2006 wove together the theories developed over the preceding decade and championed a new empirical approach to investigating behaviour. The key element of this approach was the use of adaptation as the central conceptual framework, which gave behavioural ecologists a precise a priori expectation: behaviours should evolve to maximise the fitness of the individuals showing those behaviours.

Krebs and Davies also stressed the importance of two other principles [27]. The first was the need to quantify variation in behaviour accurately. Drawing attention to the new quantitative work that was being performed in some areas of ethology [28,29], they showed how this approach could be applied to a variety of behaviours. The second principle was to use subtle variation among individuals to test adaptive hypotheses. With the notable exception of some primatological studies [30], previous ethological studies had tended to regard all individuals of a species as behaving in the same way. By contrast, behavioural ecologists tested the consequences of individual variation in behaviour on subsequent reproduction and survival.

This combination of a testable adaptive framework and a quantitative empirical approach led to huge growth in behavioural ecological research during the late 1970s and 1980s. Foraging strategies and sex ratios emerged as key battle grounds regarding the effectiveness of optimality models [31,32]. By the beginning of the $1990 \mathrm{~s}$, the consensus within the field was that simple optimality models were often remarkably accurate, suggesting that such models captured the essential payoffs, tradeoffs and constraints that determine behavioural evolution $[33,34]$. Here I ask, what has happened in behavioural ecology since then? Have behavioural ecologists simply continued to study finer and finer details of foraging behaviour and sex ratios, or have they moved on to tackle new questions of broad conceptual importance?

\section{The evolution of behavioural ecology}

Behavioural ecology has changed in terms of both the broad topics and the specific questions that it addresses. Several of the original foci of behavioural ecology, such as optimal foraging, have become relatively less fashionable (Figure 1a). Other topics have already gone through boomand-bust cycles, even within the short history of the field, with fluctuating asymmetry being a striking example (Figure 1a). However, these declining areas of activity have quickly been replaced by interest in other topics, some of which lie outside traditional definitions of behaviour, such as host-parasite interactions (Figure 1b). Also, a few of the original puzzles have 


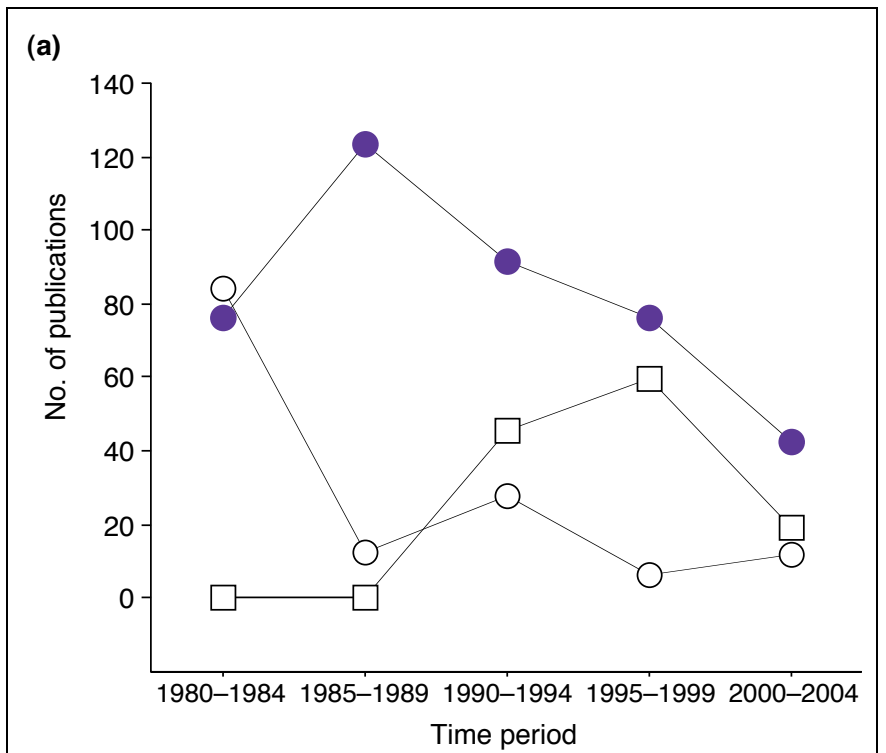

(b)

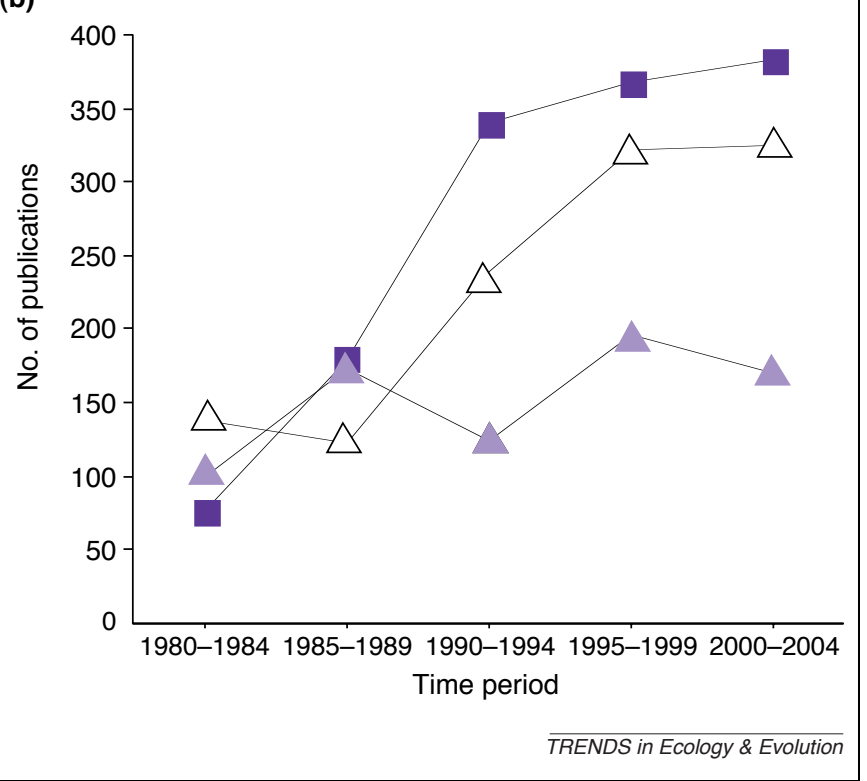

Figure 1. Differences in the pattern of publication among behavioural ecological topics over the past 25 years. (a) Topics declining in relative frequency over time (open circles, optimal foraging; closed circles, mating systems; open squares, fluctuating asymmetry). (b) Topics increasing over the same period (closed squares, sexual selection; open triangles, host-parasite interactions; closed triangles, animal signals). The number of publications is the number of papers on a topic per 10000 papers published in the field during the period in Behavioral Ecology, Animal Behaviour and Behavioral Ecology and Sociobiology. Data are based on searches of titles only from the ISI Web of Knowledge ${ }^{\text {rix }}$ (http://wok. mimas.ac.uk). Searches were performed in November 2005 using the following terms: optimal foraging, optimal forag*; Mating systems, mating system* or polyg* or polya*; Fluctuating asymmetry, fluctuating asymmetry; Sexual selection, sexual selection or mate choice or mating success; Host-parasite, parasit* or immuno*; Animal signals, signal* ${ }^{*}$.

retained their interest. Sexual selection in birds, for instance, remains a major area of activity. But behavioural ecology is not just the study of sexual selection in birds: as a field, behavioural ecology tackles a range of behaviours, and makes use of a variety of organisms (Figure 2a).

There has also been a shift in the type of questions being posed. Some of these shifts in emphasis are idiosyncratic to particular topics, but my view is that there are also some general trends. I detect a growing appreciation of studies that attempt to estimate the relative importance of competing proximate mechanisms, that use long-term databases to understand the demographic consequences of behavioural variation, or that explain the ecological basis of differences in behaviour among species (Table 1). This is true even for topics of long-standing interest, such as sexual selection, where the goal posts have now moved on from simply demonstrating that sexual ornaments are used as cues in mate choice, to estimating the relative importance of indirect (genetic) and direct (nongenetic) benefits to mate choice [35], or the role of sexual selection in speciation (Table 1). Similarly, whereas previous studies of cooperation have revealed that apparent cases of phenotypic altruism within species are in fact genetically selfish, a new challenge is to discover whether the mechanisms responsible for cooperation are common across different taxonomic groups, or across different levels of organisation (Table 1).

\section{Molecular tools}

Behavioural ecology has also changed in terms of the types of tools used to investigate animal behaviour. One obvious one is the application of molecular markers to behavioural questions [36,37] (Figure 2b). When Krebs and Davies wrote the first editions of their textbooks, metaphorical selfish genes were about as close as they got to molecular biology [26,27]. By the time of the third edition of Behavioural Ecology: An Evolutionary Approach in 1991, there was a DNA fingerprint on the front cover [38]. Given the fondness of behavioural ecologists for birds and sexual selection, it is not surprising that the molecular revolution in behavioural ecology was first felt in the study of mating systems in birds, where the widespread application of methods for assigning genetic paternity has overturned the dogma that birds are largely monogamous [39].

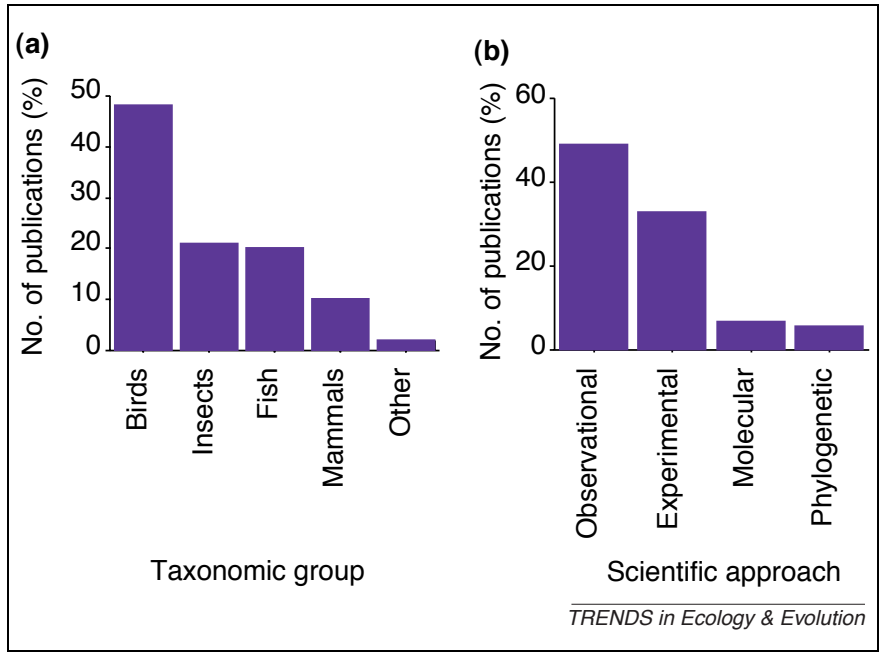

Figure 2. Approaches used in modern behavioural ecology. (a) Taxonomic affinity of study organisms. (b) Scientific method used. The number of publications is measured as a percentage of the total papers published between 2001 and 2005 in Behavioral Ecology, Animal Behaviour and Behavioral Ecology and Sociobiology. Data are based on searches on both the titles and abstracts from the ISI Web of Knowledge $^{\mathrm{Tx}}$ (http://wok.mimas.ac.uk). Searches were performed in November 2005 using the following terms: Birds, bird* or avian; Mammals, mammal*; Fishes, fish* or pisces; Reptiles, reptil* or lizard* or snake*; Insects, insect* or butterfly* or moth* or grasshopper* or cricket* or fly or flies; Observational studies, observation* or correlation*; Experimental studies, experiment* or manipulat*; Molecular studies, molecular or fingerprint* or DNA or nucle* or satellite*; Comparative studies, comparative or phylog*. 
Table 1. A personal list of questions in behavioural ecology

\begin{tabular}{|c|c|c|c|}
\hline Topic & Questions answered satisfactorily & & Questions remaining \\
\hline \multirow{4}{*}{$\begin{array}{l}\text { Adaptation and } \\
\text { optimality }\end{array}$} & Can simple adaptive models help explain complex behaviours? & Yes & Are behaviours typically at adaptive equilibria? \\
\hline & $\begin{array}{l}\text { Are there constrains to behavioural adaptation? } \\
\text { Is gene-level selection typically more useful in explaining }\end{array}$ & Yes & $\begin{array}{l}\text { Does genetic architecture limit the rate or direction of evol- } \\
\text { utionary change? }\end{array}$ \\
\hline & behaviour than group-level selection? & Yes & When is the phenotypic gambit safe? \\
\hline & & & Does gene flow inhibit behavioural adaptation? \\
\hline \multirow{5}{*}{$\begin{array}{l}\text { Sexual selection } \\
\text { and signals }\end{array}$} & Are the runaway process and the handicap principle plausible? & Yes & Are genetic benefits of mate choice greater than direct benefits? \\
\hline & Do females commonly show active mate choice? & Yes & Why are sexual ornaments often condition dependent? \\
\hline & Are some traits consistently favoured through mate choice? & Yes & Why do species have multiple sexual ornaments? \\
\hline & Can there be genetic benefits to female choice? & Yes & Is sexual selection important in speciation? \\
\hline & Can there be nongenetic benefits of female choice? & Yes & \\
\hline \multirow[t]{4}{*}{ Life histories } & Are there life-history tradeoffs? & Yes & Are life history tradeoffs due to genetic pleiotropy? \\
\hline & Are phenotypic observations sufficient to show these? & No & Is phenotypic plasticity adaptive? \\
\hline & Do life-history tradeoffs vary across species? & Yes & What factors determine interspecific variation in life histories? \\
\hline & Is variation among individuals in life history often adaptive? & Yes & $\begin{array}{l}\text { How common are transgeneration effects? } \\
\text { Is senescence adaptive? }\end{array}$ \\
\hline Cooperation & Is cooperation typically directed towards genetic kin? & Yes & What determines interspecific variation in cooperative behaviour? \\
\hline \multirow[t]{3}{*}{ and altruism } & Are there examples of non-kin benefits to cooperation? & Yes & Are kin benefits more important than direct benefits? \\
\hline & Does kin conflict also occur in social groups? & Yes & Which individuals are in control in animal societies? \\
\hline & Is cooperation nonrandom with respect to phylogeny? & Yes & $\begin{array}{l}\text { Are explanations common across taxa, or across hierarchical } \\
\text { levels of organisation? }\end{array}$ \\
\hline & Are there tradeoffs between immunity and life history? & Yes & Do host-parasite interactions maintain genetic variation? \\
\hline \multirow{2}{*}{ interactions } & Is there genetic variance in parasite resistance? & Yes & Is it possible to measure overall host immunocompetence? \\
\hline & Do hosts and parasites coevolve? & Yes & Are there 'good genes' for parasite resistance? \\
\hline
\end{tabular}

Molecular techniques are now routine in the investigation of behaviour, as illustrated by the recent findings of cryptic differences between populations in large-scale patterns of migration behaviour [40].

\section{Proximate mechanisms}

Behavioural ecologists are also making increasing use of techniques from other areas of cellular and molecular biology. In large part, this is a result of an increasing interest in the proximate mechanisms that determine behaviour [41]. One area receiving particular attention is that of ecological immunology $[42,43]$, where techniques from medicine have now been used to test theories linking immunocompetence with sexual ornamentation [44], colouration [45] and life histories [46]. The rush into a new area is not without its problems and several authors have cautioned about an over-reliance on a limited number of rather crude techniques that assay only one particular aspect of immunity [47,48]. It is worrying, for instance, that we still know so little about what these simple immune assays tell us about resistance to real parasites in wild populations, how different aspects of immunity interact, or the genetic basis of links between immune responses and traits such as body condition and sexual ornamentation.

\section{Phylogenetic approach}

An analytical tool that has a rich history in behavioural ecology but that is now being applied with increasing sophistication is that of phylogenetic comparative techniques (Figure 2b). Recent advances are based on the development of methods designed to test for links between traits that vary in a complex manner among closely related species, of which behavioural traits are a prime example [49,50]. Together with new molecular phylogenies, large-scale behavioural databases and fast computers, these new comparative techniques have generated renewed interest in the comparative approach. In addition to increasingly sophisticated analyses of well established questions regarding social organisation and life histories
[51], there is an exciting thrust towards the testing of the role of behaviour in determining large-scale patterns of speciation and extinction [52,53]. Recent comparative studies of cichlid fish, for instance, have demonstrated the potential role of male mating behaviour in the famous radiations of the East African lakes [54].

\section{Future challenges}

'Behavioural ecology is the soft underbelly of evolutionary biology'

\section{David Reznick}

For a field so heavily influenced by evolutionary thinking, behavioural ecology shows a surprising ignorance of quantitative genetics. With a few notable exceptions [55], it is still relatively rare to read a paper in a behavioural ecological journal, or hear a talk at a behavioural ecological conference, that contains information about the genetic relationships among traits. Instead, behavioural ecologists typically assume, first, that the observed phenotypic patterns of behaviour accurately reflect the underlying genetic patterns and, second, that the details of genetic architecture will not seriously influence the evolution of those behaviours. Krebs and Davies characterised this attitude as 'think of the strategies and let the genes look after themselves' [27], whereas Grafen formalised it as the 'phenotypic gambit' [56].

The phenotypic gambit should be safe under some circumstances, such as when studying a behaviour that is at a long-term evolutionary equilibrium. This is because, given enough time, evolution should lead to behavioural adaptation irrespective of the underlying genetic architecture [34]. In other circumstances, however, the difference between phenotypic and genetic patterns can be crucial. In the study of sexual selection, for instance, it matters a great deal whether a link between the showy ornamentation of the father and the longevity of his son is due to the good genes of the father or to his attentive parental care $[35,57]$. More generally, it might be 
dangerous to assume that all the behaviours that we observe are at evolutionary equilibria; once we become interested in the evolutionary dynamics of behaviour then genetics again become potentially important. This is because selection theory predicts that genetic correlations among traits are likely to be common and that these correlations can affect the evolution of individual traits $[58,59]$. Indeed, a recent reassessment of the influence of genetic limits on evolutionary change advocates that a multivariate approach is vital to understanding the evolution of complex traits, and suggests that the potential for evolutionary change is often limited by a lack of genetic variation in the multidimensional direction favoured by selection [60].

\section{Genetic basis of behaviour}

How can behavioural ecology respond to the increasing need for quantitative genetic information? The challenge is not trivial because the types of traits that are of interest to behavioural ecologists are likely to have low genetic heritability and/or complex genetic correlations with other traits. Also, whereas traditional quantitative genetic studies can use experimental breeding designs to tease apart genetic and environmental effects, such experiments are usually prohibitively demanding in wild populations. It is particularly exciting, therefore, to see the development of new techniques for obtaining quantitative genetic information about complex traits in wild populations.

One such technique is the incorporation of pedigree information into statistical models to estimate quantitative genetic parameters [61]. This 'animal model' approach has already been used to great effect in a some well studied populations, estimating the heritability of fitness in the red deer Cervus elaphus of Rum [62] and the genetic correlation between life-history parameters in the Gotland collared flycatchers Ficedula hypoleuca [63]. The fact that the technique has so far been limited to populations that have been the subject of long-term studies is no coincidence because they typically require a multigenerational pedigree. Even the requirement for a pedigree can be dropped, however, under another new approach that proposes the use of molecular markers to reconstruct genetic relationships among individuals and then use statistical models to extract information about quantitative genetic parameters [64]. The potential promise of this 'marker-based' approach to behavioural ecology is substantial, but it remains far from clear whether it can deliver robust parameter estimates from wild populations of mobile animals. Although there have been few empirical tests to date, the available evidence suggests the animal model approach will have the larger impact on behavioural ecological research [65].

An alternative method for obtaining behavioural genetic information is the candidate gene approach, which is based on the finding that some complex behaviours are strongly influenced by a small number of genes of large effect [66]. Some of the best examples of this approach come from the study of social behaviour, where it has now been shown that behaviours as diverse as social hierarchies and mate recognition can be determined by such genes [67]. In the fire ant Solenopsis invicta, for instance, a single genetic element is responsible for determining variation in an important aspect of colonylevel social organization [68]. It now remains to be discovered how many other behaviours have a similarly simple genetic basis, and whether the candidate gene approach can be successfully extended to organisms where genetic resources are more limited.

\section{Model organisms}

Another potential solution to the need for genetic information would be for behavioural ecologists to join mainstream biology in the use of model organisms. Behavioural ecology has been informed by studies based on Drosophila, such as the recent demonstration of dynamic sexual conflict [69], but such examples remain relatively rare in behavioural ecological journals. Of more than 2500 articles published in the three leading behavioural ecological journals between 2001 and 2005, $<2 \%$ made use of traditional model animals such as the nematode worm Caenorhabdites elegans; the fruit fly Drosophila melanogaster; the zebra fish Danio rerio; the chicken Gallus domesticus and the mouse Mus musculus. Why is this? In part it is probably a reflection of the fact that behavioural ecologists are genuinely more interested in the behaviour of wild organisms. Although traditional models species have many other useful attributes, their natural history in the wild is typically very poorly known. But that cannot be the whole story because behavioural ecology also makes extensive use of laboratory studies, particularly of invertebrates and fish (Figure 2a). My feeling is that behavioural ecologists have shunned model organisms simply because of cultural tradition.

Whatever the cause, the result has been that behavioural ecology has failed to make use of the wealth of genetic information accumulated in the biomedical literature, or exploit the genomic resources already available for commercially important model species. The use of model organisms remains a largely unexplored route in behavioural ecology, but surely one of great promise [35]. Indeed, even for those studies requiring wild populations, there is nothing to stop behavioural ecology developing its own model systems, based either on particularly widespread taxa or on close relatives of the traditional models.

\section{Replication across studies}

Increased use of model organisms in behavioural ecology would also help to deal with another important limitation of the field, which is the lack of precise replication across laboratories. This problem is certainly not unique to behavioural ecology per se but the use by researchers of an extraordinary diversity of study species makes it particularly difficult to replicate important findings. In other biological fields, the use of model organisms enables precise comparisons between studies and there is a culture for researchers to be wary of a potentially important discovery until it has been confirmed in other laboratories. By contrast, in behavioural ecology the lack of model systems means that even the classic studies are very rarely subject to robust scrutiny. 
One potentially useful development in this area is the importing of meta-analyses from the medical and social sciences [70]. Meta-analyses are statistical procedures designed to test the generality of support for a particular hypothesis by comparing results across a large number of empirical studies while simultaneously controlling for variation in potentially confounding factors, such as sample size and experimental technique. So far, the application of meta-analyses to behavioural ecological questions has been relatively limited, but it has been used to good effect in areas including adaptive sex ratios and fluctuating asymmetry [71]. At its best, meta-analyses might enable behavioural ecologists to continue to study a wide variety of species while simultaneously performing tests of generality.

\section{Conclusions}

One of the most important developments regarding behavioural ecology is that the adaptationist approach has now been applied to many other fields and to topics as diverse as the organisation of genomic elements, immunological cascades and human demography. It would be too much to claim that behavioural ecologists are entirely responsible for this because the core principles of the modern adaptationist approach clearly go back at least as far as Fisher and Haldane, but I think behavioural ecology has had a role in making this approach accessible and popular.

Within the field of behavioural ecology itself, a new series of questions has emerged to replace those that have already been answered (Table 1) Many of these new questions are of a subtly different type and require a more detailed understanding of the genetic and physiological mechanisms that underlay behavioural traits. Here, I have argued that, to tackle these outstanding questions, behavioural ecologists would benefit greatly from embracing the opportunities offered by model organisms and evolutionary genetics.

\section{Acknowledgements}

I thank David Reznick for allowing me to quote from his conversation with Locke Rowe; and Goran Arnqvist, Mark Blows, Andrew Bourke, Terry Burke, Tim Clutton-Brock, Tim Coulson, Andrew Cockburn, Innes Cuthill, Nick Davies, Charles Godfray, Jarrod Hadfied, John Krebs, Russ Lande, Shai Meiri, Ally Phillimore, Ben Sheldon and Andrew Read for discussion or comments.

\section{References}

1 Krebs, J.R. and Davies, N.B., eds (1984) Behavioural Ecology: An Evolutionary Approach (2nd edn), Blackwell Scientific Press

2 Hamilton, W.D. (1964) The genetical evolution of social behaviour, I, II. J. Theor. Biol. 7, 1-52

3 MacArthur, R.H. and Pianka, E.R. (1966) On optimal use of a patchy environment. Am. Nat. 100, 603-609

4 Williams, G.C. (1966) Adaptation and Natural Selection, Princeton University Press

5 Hamilton, W.D. (1967) Extraordinary sex ratios. Science 156, 477-488

6 Hamilton, W.D. (1971) Geometry for selfish herd. J. Theor. Biol. 31, 295-311

7 Trivers, R.L. (1971) Evolution of reciprocal altruism. Q. Rev. Biol. 46, $35-57$

8 Trivers, R.L. (1972) Parental investment and sexual selection. In Sexual Selection and the Descent of Man (Campbell, B., ed.), pp. 136-170, Aldine Press

9 Maynard Smith, J. and Price, G.R. (1973) The logic of animal contests. Nature 246, 15-18
10 Trivers, R.L. and Willard, D.E. (1973) Natural selection of parental ability to vary sex ratio of offspring. Science 179, 90-92

11 Trivers, R.L. (1974) Parent-offspring conflict. Am. Zool. 14, 249-264

12 Maynard Smith, J. and Parker, G.A. (1976) Logic of asymmetric contests. Anim. Behav. 24, 159-175

13 Emlen, S.T. and Oring, L.W. (1977) Ecology, sexual selection, and evolution of mating systems. Science 197, 215-223

14 Maynard Smith, J. (1978) Evolution of Sex, Cambridge University Press

15 Fisher, R.A. (1930) The Genetical Theory of Natural Selection, Clarendon Press

16 Haldane, J.B.S (1932) The Causes of Evolution, Longmans

17 Hinde, R.A. (1956) The biological significance of the territories of birds. Ibis $98,340-369$

18 Tinbergen, N. (1963) On aims and methods of ethology. Zeit. Tierpsychol. 20, 410-433

19 Crook, J.H. (1964) The evolution of social organisation and visual communication in the weaver birds (Ploceinae). Behaviour 10, 1-178

20 Lack, D.L. (1968) Ecological Adaptations for Breeding in Birds, Methuen

21 Orians, G.H. (1969) On the evolution of mating systems in birds and mammals. Am. Nat. 103, 589-603

22 Parker, G.A. (1970) Sperm competition and its evolutionary consequences among the insects. Biol. Rev. 145, 525-567

23 Wilson, E.O. (1971) Insect Societies, Belknap Press, Harvard University Press

24 Wilson, E.O. (1975) Sociobiology: The New Synthesis, Belknap Press, Harvard University Press

25 Dawkins, R. (1976) The Selfish Gene, Oxford University Press

26 Krebs, J.R. and Davies, N.B., eds (1978) Behavioural Ecology: An Evolutionary Approach (1st edn), Blackwell Scientific Press

27 Krebs, J.R. and Davies, N.B. (1981) An Introduction to Behavioural Ecology, 1st edn, Blackwell Scientific Press

28 Krebs, J.R. et al. (1972) Flocking and feeding in the great tit Parus major: an experimental study. Ibis 114, 507-530

29 Neill, S.R.S.J. and Cullen, J.M. (1974) Experiments on whether schooling by their prey affects the hunting behaviour of cephalopod and fish predators. J. Zool. 172, 549-569

30 Goodall, J. (1968) The behaviour of free-living chimpanzees in the Gombe Stream Reserve. Anim. Behav. Monogr. 1, 163-311

31 Gould, S.J. and Lewontin, R.C. (1979) Spandrels of San-Marco and the Panglossian paradigm - a critique of the adaptationist program. Proc. R. Soc. B 205, 581-598

32 Orzack, S.H. and Sober, E. (1994) How (not) to test an optimality model. Trends Ecol. Evol. 9, 265-267

33 Stephens, D.W. and Krebs, J.R. (1987) Foraging Theory, Princeton University Press

34 Parker, G.A. and Smith, J.M. (1990) Optimality theory in evolutionary biology. Nature $348,27-33$

35 Andersson, M. and Simmons, L.W. (2006) Sexual selection and mate choice. Trends Ecol. Evol. 21, doi:10.1016/j.tree.2006.03.015

36 Burke, T. (1989) DNA Fingerprinting and other methods for the study of mating success. Trends Ecol. Evol. 4, 139-144

37 Queller, D.C. et al. (1993) Microsatellites and kinship. Trends Ecol. Evol. 8, 285-288

38 Krebs, J.R. and Davies, N.B., eds (1991) Behavioural Ecology: An Evolutionary Approach, (3rd edn) Blackwell Scientific Press

39 Griffith, S.C. et al. (2002) Extra-pair paternity in birds: a review of interspecific variation and adaptive function. Mol. Ecol. 11, 2195-2212

40 Ruegg, K.C. and Smith, T.B. (2002) Not as the crow flies: a historical explanation for circuitous migration in Swainson's thrush (Catharus ustulatus). Proc. R. Soc. B 269, 1375-1381

41 Robinson, G.E. (1999) Integrative animal behaviour and sociogenomics. Trends Ecol. Evol. 14, 202-206

42 Sheldon, B.C. and Verhulst, S. (1996) Ecological immunology: costly parasite defences and trade-offs in evolutionary ecology. Trends Ecol. Evol. 11, 317-321

43 Viney, M.E. et al. (2005) Optimal immune response: immunocompetence revisited. Trends Ecol. Evol. 20, 665-669

44 Folstad, I. and Karter, A.J. (1992) Parasites, bright males, and the immunocompetence handicap. Am. Nat. 139, 603-622

45 Olson, V.A. and Owens, I.P.F. (1998) Costly sexual signals: are carotenoids rare, risky or required? Trends Ecol. Evol. 13, 510-514 
46 Martin, T.E. et al. (2001) Does clutch size evolve in response to parasites and immunocompetence? Proc. Natl. Acad. Sci. U. S. A. 98, 2071-2076

47 Owens, I.P.F. and Wilson, K. (1999) Immunocompetence: a neglected life history trait or conspicuous red herring? Trends Ecol. Evol. 14, 170-172

48 Norris, K. and Evans, M.R. (2000) Ecological immunology: life history trade-offs and immune defense in birds. Behav. Ecol. 11, 19-26

49 Freckleton, R.P. et al. (2002) Phylogenetic analysis and comparative data: a test and review of evidence. Am. Nat. 160, 712-726

50 Blomberg, S.P. et al. (2003) Testing for phylogenetic signal in comparative data: behavioral traits are more labile. Evolution 57, 717-745

51 Bennett, P.M. and Owens, I.P.F. (2002) Evolutionary Ecology of Birds: Life Histories, Mating Systems and Extinction, Oxford University Press

52 Barraclough, T.G. and Nee, S. (2001) Phylogenetics and speciation. Trends Ecol. Evol. 16, 391-399

53 Fisher, D.O. and Owens, I.P.F. (2004) The comparative method in conservation biology. Trends Ecol. Evol. 19, 391-398

54 Seehausen, O. and Schluter, D. (2004) Male-male competition and nuptial-colour displacement as a diversifying force in Lake Victoria cichlid fishes. Proc. R. Soc. B 271, 1345-1353

55 Boake, C.R.B., ed. (1994) Quantitative Genetic Studies of Behavioral Evolution, University of Chicago Press

56 Grafen, A. (1984) Natural selection, kin selection and group selection. In Behavioural Ecology: An Evolutionary Approach (2nd edn) (Krebs, J.R. and Davies, N.B., eds), pp. 62-84, Blackwell Scientific Press

57 Kirkpatrick, M. and Ryan, M.J. (1991) The evolution of mating preferences and the paradox of the lek. Nature 350, 33-38

58 Lande, R. (1982) A quantitative genetic theory of life history evolution. Ecology 63, 607-615
59 Lande, R. and Arnold, S.J. (1983) The measurement of selection on correlated characters. Evolution 37, 1210-1226

60 Blows, M.W. and Hoffmann, A.A. (2005) A reassessment of genetic limits to evolutionary change. Ecology 86, 1371-1384

61 Kruuk, L.E.B. (2004) Estimating genetic parameters in natural populations using the 'animal model'. Phil. Trans. R. Soc. B 359, 873-890

62 Kruuk, L.E.B. et al. (2000) Heritability of fitness in a wild mammal population. Proc. Natl. Acad. Sci. U. S. A. 97, 698-703

63 Merilä, J. et al. (2001) Cryptic evolution in a wild bird population. Nature 412, 76-79

64 Ritland, K. (2000) Marker-inferred relatedness as a tool for detesting heritability in nature. Mol. Ecol. 9, 1195-1204

65 Garant, D. and Kruuk, L.E.B. (2005) How to use molecular marker data to measure evolutionary parameters in wild populations. Mol. Ecol. 14, 1843-1859

66 Fitzpatrick, M.J. et al. (2005) Candidate genes for behavioural ecology. Trends Ecol. Evol. 20, 96-104

67 Robinson, G.E. et al. (2005) Sociogenomics: social life in molecular terms. Nat. Rev. Genet. 6, 257-270

68 Ross, G.R. and Keller, L. (1998) Genetic control of social organisation in an ant. Proc. Natl. Acad. Sci. U. S. A. 95, 14232-14237

69 Rice, W.R. (1996) Sexually antagonistic male adaptation triggered by experimental arrest of female evolution. Nature 381, 232-234

70 Arnqvist, G. and Wooster, D. (1995) Meta-analysis - synthesizing research findings in ecology and evolution. Trends Ecol. Evol. 10, 236-240

71 Palmer, A.R. (2000) Quasireplication and the contract of error: lessons from sex ratios, heritabilities and fluctuating asymmetry. Annu. Rev. Ecol. Evol. System. 31, 441-480

\section{Forthcoming Conferences}

Are you organizing a conference, workshop or meeting that would be of interest to TREE readers? If so, please e-mail the details to us at TREE@elsevier.com and we will feature it in our Forthcoming Conference filler.

\section{July-4 August 2006}

Fifth International Conference on Stickleback Behavior \&

Evolution, University of Alaska, Anchorage, USA

http://fish.uoregon.edu/sb/stickleback2006

\section{6-10 August 2006}

Animal Behaviour Society, Salt Lake City, USA

http://www.animalbehavior.org/ABS/Program/Snowbird05/

\section{6-11 August 2006}

91st ESA Annual Meeting, Memphis, USA

http://www.esa.org/memphis/

\section{3-19 August 2006}

24th International Ornithological Congress, Hamburg,

Germany

http://www.i-o-c.org

22-26 August 2006

1st European Congress of Conservation Biology, Eger, Hungary http://www.eccb2006.org/

\section{4-6 September 2006}

ECBB: 3rd Joint European Conference on Behavioural

Biology, Belfast, Northern Ireland

http://asab.nottingham.ac.uk/meetings/asab.php

4-8 September 2006

41st European Marine Biology Symposium, University

College Cork, Ireland

(http://www.embs41.ucc.ie/)

5-7 September 2006

British Ecological Society Annual Meeting, University of

Oxford, UK

http://www.britishecologicalsociety.org/
10-14 September 2006

American Society for Fish Biology, Lake Placid, USA http://www.fisheries.org/html/index.shtml

\section{3-7 October 2006}

American Ornithologist Union, Veracruz, Mexico http://www.naoc2006.org/

\section{8-21 October 2006}

Society of Vertebrate Palaeontology, Ottawa, Canada http://www.vertpaleo.org

\section{7-19 November 2006}

E-Bird International meeting. Coping with environmental change: integrating avian ecology and endocrinology. University of Glasgow UK http://e-bird.cefe.cnrs.fr/final-workshop.htm

\section{4-7 December 2006}

5th International Conference on Ecological Informatics, Santa Barbara, CA, USA http://www.isei5-conference.elsevier.com

\section{7}

\section{2-18 August 2007}

30th Congress of the International Association of Theoretical and Applied Limnology, Montréal, Canada

(http://www.sil2007.org)

\section{0-25 August 2007}

11th Congress of The European Society for Evolutionary

Biology, Uppsala, Sweden

(http://www.eseb.org/) 